\title{
Discussion on the Power List System
}

\author{
Tong Yixu \\ Law school of Nanjing University, jiangsu province, in China
}

892922567@qq.com

Keywords: List t Power List; Existing Problem ; Route Guidance.

\begin{abstract}
As a unique innovation system, the list of powers enables the government to effectively exercise administrative power and enhance the transparency of government power. The implementation of the power list system is to pursue the reduction of government and decentralization ,establish limited government, service-oriented government and rule of law government. However, the position of power list in our legal system is not clear, there are some limitations. Based on the value proposition of the power list system, this paper discusses the implementation of the further optimization of the power list system and gradually adjusts the path of the power inventory system.
\end{abstract}

\section{The general theory of the power list system}

The third plenary session of the 18 through "the central committee of the communist party of China on comprehensively deepen reform certain major issue decision" clearly put forward "by local government and its department of power system, in accordance with the public power running processes", governments at all levels to develop and launch their own power list. The implementation of the power list system has achieved the expected effect, and in the meantime, the limitation of the power list system should be seen.

Listing of power system, refers to the government or other departments at all levels to power the supervision for the purpose, on the actual rights stipulated in the laws and regulations under the premise of all-round carding, will power and responsibility main body functions and powers, rights, legal basis and specification list, on the basis of listing and the public, in order to achieve and to delegate the effect of the system is made. In general, the list of powers is just an enumeration of the power of the executive body itself. However, the current system power list is not presented in the text of laws and regulations, and there are no strict laws and regulations on its effectiveness and operation.

The list of powers is made by the official government, and the government information is open to the public. The content of the information disclosure mainly includes the administrative powers of the government and the process procedures of the government. This is an important content of government information publicity, the government information disclosure regulations stipulated in article 9 the administrative organ shall take the initiative to reflect publicly this administrative organs set up and work flow and so on situation of government information. Second, the power list has the nature of administrative guidance, the government announced through the scope and work flow of power, guide the administrative relative to participate in the administrative law, refused to illegal administrative interference outside the listing. The list of powers has no compulsion for the relative, and the social public has the right to question the executive power on the list, or to add amendments to the list of powers. Finally, most power lists have the nature of administrative normative documents. Power will list document issued in the form of government, each administrative power to a specific department and clear most of the power list Suggestions to matters of the government's power to adjust, usually involving government administrative relative person's rights and obligations. The scope of the government's exercise of power must be reflected in the list of lists, exercising power according to the list of documents and not exceeding the authority. 


\section{The existing problem of the power list system}

Firstly, the government has ruled that its rights do not comply with basic legal principles. Our constitution stipulates that all power belongs to the people, and the government itself is not a legal source of rights. Government power comes from the people's award and is set by the law. The government is not allowed to modify it arbitrarily, which is the basic logic of the rule of law society. It is not the government or the government itself, but the organs of power, the people's congress. Therefore, the list of powers is not a normative legal document.

Secondly, the public subject is extended by the legislature to the executive branch. The administrative authority, promulgation and public subject can only be the legislature, and the public subject of the list of powers is the government departments at different levels. On a daily basis, the list of powers is publicly available at the county level. The list of powers, with the lowest administrative levels at the county level, will cost a lot of resources, and the list of powers that need to be developed nationwide is enormous. Moreover, due to the limitation and diversity of human cognition, it is of great challenge to enumerate the administrative powers scattered in different laws and regulations. Despite the number of administrative power much the fact that there is an objective, but in terms of public way, and the legislature, compared to the unification of public administrative agencies they are effective, but the legislature of the public can greatly reduce the administrative cost.

Then, the document abolishing law, lack of legal thinking. In announcements of power lists, governments around the world have made clear that government departments are forbidden from exercising power over the list of powers. The executive power list is issued in the form of administrative documents, while the setting of administrative powers is mainly the laws and regulations. From the perspective of legal effectiveness, the power list does not exclude the application of the power setting basis outside the list. From the perspective of the value level of the power list system, the power list can't function better than the statutory principle. In practice, the rights on the list can't be matched with the government's functions due to the clearing of omissions and the ambiguity of the legal basis. Method without authorization for statutory functions and powers must be duty, the legal responsibility, to make exclusive rules, as administrative thinking for the rule of law thinking, inevitably brings to the administrative department of the illegal risk in system level. To avoid these problems, the list of powers should be regarded as a government information rather than an administrative document. Whether or not a list of powers is published, the basis for administration and administrative enforcement is legal, not a list of powers. To sum up, the implementation of the list of powers does not equal to the list administration, and the list of powers should not be delegated or adjusted. Because delegating or adjusting administrative power involves numerous administrative legal issues, it is necessary to adjust laws and regulations from the level of legal authorization, which cannot be resolved within the institutional framework of the power list.

Finally, China’s power list system lacks accountability mechanism. China’s power list system has just begun, many systems are not perfect, especially outstanding performance in accountability system. The purpose of implementing the power list system is to assume the cage of the system of power, thus realizing the purpose of restricting the administrative power. Therefore, to make the list system play a real role, it is also crucial to improve the accountability system. The right must have the responsibility, the right to supervise, the abuse to pursue. Some places do not have the right to use the power list system or violate the power list system, and there is no corresponding accountability system to match the system. In this case, the listing will appear power is abused, violated the rules of the listing of power within the limits of their authority or beyond power list, do not have corresponding responsibility shall be investigated and punished, reduce the cost of illegal, lead to behavior person knowingly, trampling on the legal bottom line, for the purpose of the listing of power system become a fantasy, makes the power list become a dead letter. 


\section{Improve the path orientation of the power list system}

In listing system in the process of the implementation of the provisions of the administrative authorities to ban all to power list items against the effectiveness of the normative documents with foreign countries, the other party with reference to the legal and valid of normative legal documents, administrative organs must be based on the provisions of the regulatory documents, and is not rely on the power list list. The main function of the listing system is to protect the legal rights of the relative and to ensure the administrative power to operate in the sunshine. If the list is not clear and the demarcation is not clear, not only the legitimacy of the list system is difficult to be improved, but the administrative authority is not efficient through the list of powers. On the one hand, with its own understanding of the executive regime, the relative person is turned away from the other party, and even gives itself very large powers, which are not easily perceived by the other party. Such as scholars Outlines that look small but beautiful or uniform power list may not clear, some head just changed name, some practice is to integrate the power of the fragmentation even for greater rights. On the other hand can also be disguised hide and escape the fulfillment of duties, as the control of administrative power is quite clear, if the administrative organ for its information advantage to maximize their own interests, the interests of the other party no real protection. When formulating the listing in the power system, therefore, must be knowledgeable about the nature of the listing and it only has enumerated the role of administrative power, does not conflict with the laws and regulations or other normative documents, administrative organs cannot under the situation of no law as the basis, only through the power of the public listing to the specific administrative act.

Administrative ACTS in administrative law are carried out by organs or organizations of specific administrative subject qualifications. The executor of administrative action is qualified as the administrative subject and is the competent administrative subject in law. Therefore, the formulation of the list of powers and the administrative functions of the administrative subject should be clearly defined in the form of law. The power list system exposes the subject of power to the sun and receives the supervision of the people. In law, therefore, should make clear with power list the range of the main body of rights, power list of administrative power exercised by which administrative body, cannot cause the confusion of power, and you must do it without power list. The listing and its department of power under the state council by the standing committee of the National People's Congress to run, but in view of the specific work, gives each department certain autonomy, discretion part of the work of the department. The power list of provincial government departments can be exercised by the standing committee of the National People's Congress, while the standing committee of the provincial people's congress, provincial governments and their working departments shall carry out specific work.

Power list as a new system, because of the execution of the system depends on the government to exercise the right to exercise and supervision, so the power list into the track of legal system is an important way of its function, namely the legalization of power list. The legalization of the power list mainly includes the following three aspects. First, is regulated by laws of power list should include the basic content, including the scope of administrative power, making the flow diagram, and the implement method of specific administrative power and the relief channels, etc., to the main body of a unified standards in power list and requirements, make its standardization of power list. To normalize and legalize the list of powers by making laws. Secondly, after the list of powers is published, it will be updated and managed in accordance with the law, and the synchronization and accuracy of the legislation will be maintained. List after the public power as a means, should be as a measure of the concrete implementation of administration according to law, perfecting the legal system shall be revised in time, according to the law of change into, change, and delete the administrative functions and powers. Thirdly, the construction and improvement of legal liability and remedy way of the subject of power list. In the process of the implementation of the power list, such as unauthorized or omission of administrative authority behavior must be investigated for legal responsibility, the responsibility must be found in the laws related to the corresponding basis, in the specific provisions of law governing power list. In addition, it is under the supervision of the administrative relative person is one of the most important ways for seek relief when the other party 
its own interests is damaged, only there is legally feasible relief channels, listing interest related party talent initiative to monitor the government's actions, watchdog role to maximum full play.

Accountability system is a system that matches the list of powers. Responsibility system including the responsibilities of government departments, is to clarify the government responsibility and boundary, perfecting power supervision system, strengthen the public service concept as the core of power and responsibility unified responsibility system. The greater the power of government, the greater the burden of responsibility. The accountability system refers to the negative consequences and the corresponding punishment that the government departments and their staff members cannot perform their duties and duties properly. And listing of power system is required at all levels of government and its department in accordance with the power to the content of the listing rules to the exercise of power, if violates the relevant regulations, beyond the scope of authorization, abuse of power, administrative inaction, then shall bear the corresponding legal responsibility and legal responsibility shall be investigated for illegal workers.

Listing system, to better adapt to and carry out power should standardize and improve the system of responsibility, first of all, the science and clarify the responsibility department, according to the practical operation of administrative power, the introduction of social public participation mechanism, widely from experts and public opinion, in accordance with the provisions of the law to government departments to the responsibility of the rationalization of the comb, and achieve seamless docking responsibilities between different departments. The construction of intersectoral collaboration has become the main development trend of the current government. Through the construction of intersectoral collaboration, government management has begun to form a new form. Second, define the main body of responsibility. The implementation of the responsibility of the administrative subject should really fall into place. As the government departments themselves, they must be responsible, constantly strengthen their sense of responsibility, mistakes must be changed, and violations must be taken into account. Third, establish accountability system. This system can break the bondage of time chain, some will only want immediate achievements or current interests and take the wrong home administrative decision of administrative subject and improve the illegal cost, did not dare to ask the private law and abuse of power. Fourth, establish accountability mechanism. Other leaders and relevant persons responsible for the serious error of decision-making and illegal exercise will not be able to get out of the law. It is necessary to set up the system of accountability and the system of power to match the system of power, so that the corruption of power can only be exposed to the sun, and the responsibility of government and the rule of law should be established.

\section{Summary}

In short, the implementation of the list of powers is conducive to the improvement of the transparency and administrative efficiency of the operation of the public power, and is favored by administrative organs at all levels. List of power system effective operation must abide by the law without authorization and authority for legal principles of administrative law, the implementation of the power system of listing must uphold the rule of law thinking, in order to promote the rule of law way. In the process of constructing the rule of law, the list of powers is the product of institutional innovation, and should define the position of the list of powers and adjust the path of the system of power inventory appropriately.

\section{References}

[1] Shen Haiping., The position of the list of powers cannot be overdone by law . Academia,200(1) , PP.126-134,2015 .

[2] luo Yacang. ,Evaluation and Improvement On Tax Admmistrative Examination and Approval of Power List System-With the State Administration of Taxation of 2014 10th Announcement for 
Analysis Template. Chinese Administrative Management , 350(6), pp.22-25,2015.

[3] Zhou Qingzhi., Control power: a utilitarian perspective - the "list of power" in county politics . Journal of Harbin Institute of Technology (social science edition) ,16(3),pp1-11,2014 .

[4] Guan Baoying: Administrative law construction of power list. Journal of zhengzhou university, 47(6), pp64-69,2014.

[5] Cui Hao .\& Sang Jiquan., The construction philosophy and responsibility of the list systemof responsibility.E dministrative Management Reform,18(6),pp61-65,2015. 